\title{
A rare cause of respiratory distress in pediatric palliative care: Thoracic Duplication Cyst
}

\author{
Nilgün Harputluoğlu${ }^{1}$, Tanju Çelik ${ }^{1}$, Günyüz Temir ${ }^{1}$, and Münevver Hoşgör ${ }^{1}$ \\ ${ }^{1}$ SBÜ Dr Behçet Uz Çocuk Hastalıkları Ve Cerrahisi Eğitim Ve Araştırma Hastanesi
}

June 22, 2021

\begin{abstract}
Gastrointestinal duplication cysts are actually rare congenital anomalies that can accompany various anomalies and are most frequently seen in the small intestine. Gastrointestinal duplication may accompany anomalies such as vertebral anomalies, spinal cord malformations. Depending on the location, symptoms such as chest pain, shortness of breath, cough, asthma-like symptoms, hemoptysis, cyanosis, vomiting, difficulty swallowing, weight loss, hematemesis and melena can be observed. To our knowledge, we report a rare case that has not been reported in pediatric palliative care. We present a case operated for diaphragmatic hernia in the neonatal period. A 3-month-old patient with respiratory distress who was followed up in pediatric palliative care was reoperated and pathologically diagnosed as gastrointestinal duplication cyst. Thoracic cysts can have a wide variety of etiology. The correct diagnosis can be made by performing further examinations and appropriate surgery.
\end{abstract}

\section{A rare cause of respiratory distress in pediatric palliative care: Thoracic Duplication Cyst}

\section{Affiliations}

Nilgün Harputluoğlu, MD, Pediatrician; Izmir Dr Behçet Uz Children's Hospital, Pediatric Palliative Care Center-Izmir/Turkey

Tanju Çelik, MD, Assoc. Prof, Izmir Dr Behçet Uz Children's Hospital, Pediatric Palliative Care CenterIzmir/Turkey

Günyüz Temir, MD, Pediatric surgeon, Izmir Dr Behçet Uz Children's Hospital, Department of Pediatric Surgery-Izmir/Turkey

Münevver Hoşgör, MD, Prof , Izmir Dr Behçet Uz Children's Hospital, Department of Pediatric SurgeryIzmir/Turkey

\section{Address correspondence to:}

\section{Nilgün Harputluoğlu}

mail: Pediatric Palliative Care Center; Dr. Behçet Uz Children's Hospital, İsmet Kaptan Region, Sezer Doğan Street, No:11, Alsancak, Konak, 35210, İzmir, Turkey.

e-mail :nilgunharputluoglu@yahoo.com.tr

phone :+905306418055

Address research: Dr. Behçet Uz Children's Hospital, İsmet Kaptan Region, Sezer Doğan Street, No:11, Alsancak, Konak, 35210, İzmir, Turkey. 
Author contribution: Each author has participated in the concept and design; analysis and interpretation of data; drafting or revising of the manuscript and that each author has approved the manuscript as submitted and agree to be accountable for all aspects of the work.

Funding source: There is no funding source.

Disclosure: The authors declare no conflict of interest.

Key Words: Gastointestinal duplication cyst, Jejunal duplication cyst, Pediatric palliative care, Respiratory Distress.

Short title: Thoracic duplication cyst in pediatric palliative care

\section{To the Editor,}

Gastrointestinal duplication cysts (GID) can occur in almost every age group, in various locations and with various symptoms, and they must be operated because they have malignant potential. Many interesting cases have been reported. However, jejunal duplication cysts are very rare. As far as we know, this is the first case of jejunal GID (jejunal) cyst followed in pediatric palliative care, examined for respiratory distress, localized in the thorax and not causing obstruction. This case reinforces the importance of knowing the symptoms of jejunal GID cases.

\section{Introduction}

Gastrointestinal duplication (GID) cysts are rare congenital anomalies that can accompany various anomalies and are most frequently seen in the small intestine (ileum, 40\%). ${ }^{1}$ They occur in the 3rd to 4 th gestational weeks of pregnancy. With the development of prenatal imaging and screening techniques, it has become easier to identify in routine 2nd-trimester screenings. ${ }^{2}$ Gastrointestinal duplication may accompany anomalies such as vertebral anomalies (hemivertebra, butterfly vertebra, spina bifida) and spinal cord malformations (diastometamyelia). ${ }^{1}$ To our knowledge, we report a rare case that has not been reported in pediatric palliative care.

\section{CASE}

A 3-month-old male baby born $3710 \mathrm{~g}$ at 38th-week from the first pregnancy of a 38-year-old mother was followed up in another center for 17 days due to respiratory distress. The baby was then referred to the neonatal intensive care unit due to the persistence of flexion contracture in the right hand, kyphoscoliosis, and respiratory distress. As a result of the examinations performed in the neonatal intensive care unit, he was operated on with a pre-diagnosis of hiatal hernia. In postnatal radiological examinations, spinal MRI revealed that the C5 vertebral corpus could not be clearly identified. In this localization, the anterior defect at the level of the C5 vertebra and the areas associated with the lung parenchymal areas in the localization adjacent to this area were observed with air-fluid leveling. This area was thought to be related to the spinal cord. Thorax CT showed that mediastinal compartments were displaced to the left. In the medial of the right hemidiaphragm, a $2 \mathrm{~cm}$ suspicious appearance in the diaphragm posteriorly and herniation of the intestinal loops to the right hemidiaphragm at this level was detected.

In operation, no hiatal hernia was observed, and it was terminated with appendectomy only. A 3-month-old baby with multiple congenital anomalies (adduction-pronation and flexion in the right arm, defect at the anterior of the C5 cervical vertebra, and anterior cervical meningomyelocele appearance) and receiving intrahood oxygen support was transferred to our pediatric palliative care center due to congenital malformation and maternal compliance.

On physical examination, his general condition was moderate, he was conscious, and his hydration was good. His weight was 3160gr (10-50p), height $52 \mathrm{~cm}(90 \mathrm{p})$, head circumference $36 \mathrm{~cm}$ (90p), apex beat 149 min, respiratory rate $52 / \mathrm{min}$, fever $36.6^{\circ} \mathrm{C}$ (axillary), blood pressure $80 / 62 \mathrm{mmHg}$, preductal Spo2 97\%, and postductal Spo2 98\% (in room air). There was respiratory distress. There were no pathological findings in 
cardiovascular, gastrointestinal and genitourinary system examinations, apart from an incision scar in the midline of the abdomen.

Due to the persistence of the cystic appearance in the chest radiography (Figure 1), advanced radiological examinations and fluoroscopy were performed. Fluoroscopy showed malrotation resulting in herniation of the jejunal loops from the medial center of the right hemidiaphragm to the right hemithorax from the hiatus level and gastroesophageal reflux. The MRI reported an enteric duplication cyst extending transdiaphragmically to the right hemithorax from the hiatus level and accompanying meningomyelocele tissue observed at the cervical level, hypoplasia/agenesis in the right hemithorax apex level, and a pre-diagnosis of the fused neurenteric cyst was suggested.

The case, was consulted again with pediatric surgery and operated again with an experienced surgeon and chairman of the department. The cystic lesion adhering to the wall at the apex of the right hemithorax was removed. In pathological examination, a small intestinal (jejunal) duplication cyst with a length of $5 \mathrm{~cm}$ and a diameter of $1.5 \mathrm{~cm}$ was reported. On the 10th postoperative day, he was discharged to his home.

\section{Discussion}

Congenital cystic lesions of the lung parenchyma have similar embryogenesis to duplication cysts. Primitive foregut origin cysts include bronchogenic cysts, duplication cysts, enterogenic cysts, neurenteric cysts, and bronchopulmonary cysts. ${ }^{3}$

Mediastinal cysts in children are generally symptomatic course. Depending on GID cysts' location, symptoms such as chest pain, shortness of breath, cough, asthma-like symptoms, hemoptysis, cyanosis, vomiting, difficulty swallowing, weight loss, hematemesis and melena can be observed. ${ }^{3}$ Rare duplication cysts were reported as three cases in a total of five years in a series, and only one of them was reported to be a thoracic cyst. ${ }^{4,5}$ In addition to chest radiography, computed tomography, and magnetic resonance images, fluoroscopy helps in diagnosis. ${ }^{6}$ Treatment is total excision of the cyst. If the cyst is related to the gastrointestinal system, this relationship should be eliminated. Even if GID cysts are asymptomatic, they should be surgically removed because of the mass effect and risk of malignancy. ${ }^{7}$ In our case, a second operation decision was made as a result of fluoroscopy, and the diagnosis of the thoracic GID (jejunal) cyst was confirmed as a result of repeated operations. Syed et al. ${ }^{8}$ reported a rare jejunal duplication cyst with obstruction. Our case is a jejunal duplication cyst in the thorax that does not cause bowel obstruction.

\section{Conclusion}

A case of jejunal duplication cyst as a rare cause of respiratory distress in pediatric palliative care. It was diagnosed because of its localization in the thorax, absence of obstruction and stable behavior. Its association with vertebral anomalies is critical, and it may be necessary to act decisively even in the operated cases.

\section{References:}

1. Bui T, Bankhart MF, Mandell GA, et al. Thoraco-abdominal enteric duplication cyst in association with neurenteric cyst, axial skeletal anomalies, and malrotation. Radiol Case Rep 2013;8:779.

2. Ben-Ishay O, Connolly SA, Buchmiller TL. Multiple duplication cysts diagnosed prenatally: case report and review of the literature. Pediatr Surg Int 2013;29:397-400.

3. Takeda S, Miyoshi S, Minami M, et al. Clinical spectrum of mediastinal cysts. Chest 2003;124:125-32.

4. Ferraro P, Martin J, Duranceau ACH. Foregut cysts of the mediastinum. In Shields TW, LoCicero J, Reed CE, Feins RH ed. General Thoracic Surgery, vol 2, 7 th ed. Philadelphia: Lippincott Williams and Wilkins; 2009:2519-30.

5. Mirza B, Ahmad S, Wasti AR, et al. Our experience with unusual gastrointestinal tract duplications in infants. African journal of Paediatric Surgery. 2014;11(4): 326-9. 
6. Savci G, Balkan E, Ozyaman T, Dogruyol H, Tuncel E. Thoracoabdominal duplication cyst: US, CT and MR findings. Eur Radiol 1997;7:382-4.

7. Chuang MT, Barba FA, Kaneko M, Tierstein AS. Adenocarcinoma arising in an intrathoracic duplication cyst of foregut origin: a case report with review of the literature. Cancer 1981;47:1887-90.

8. Syed KM, Al Faqeeh AA, Almas T, Alaeddin H, Al-Awaid AH. Cystic Nontubular Jejunal Duplication Cyst Presenting As Acute Intestinal Obstruction: A Surgical Challenge. Curesu. 2021; 13(3):e13994.

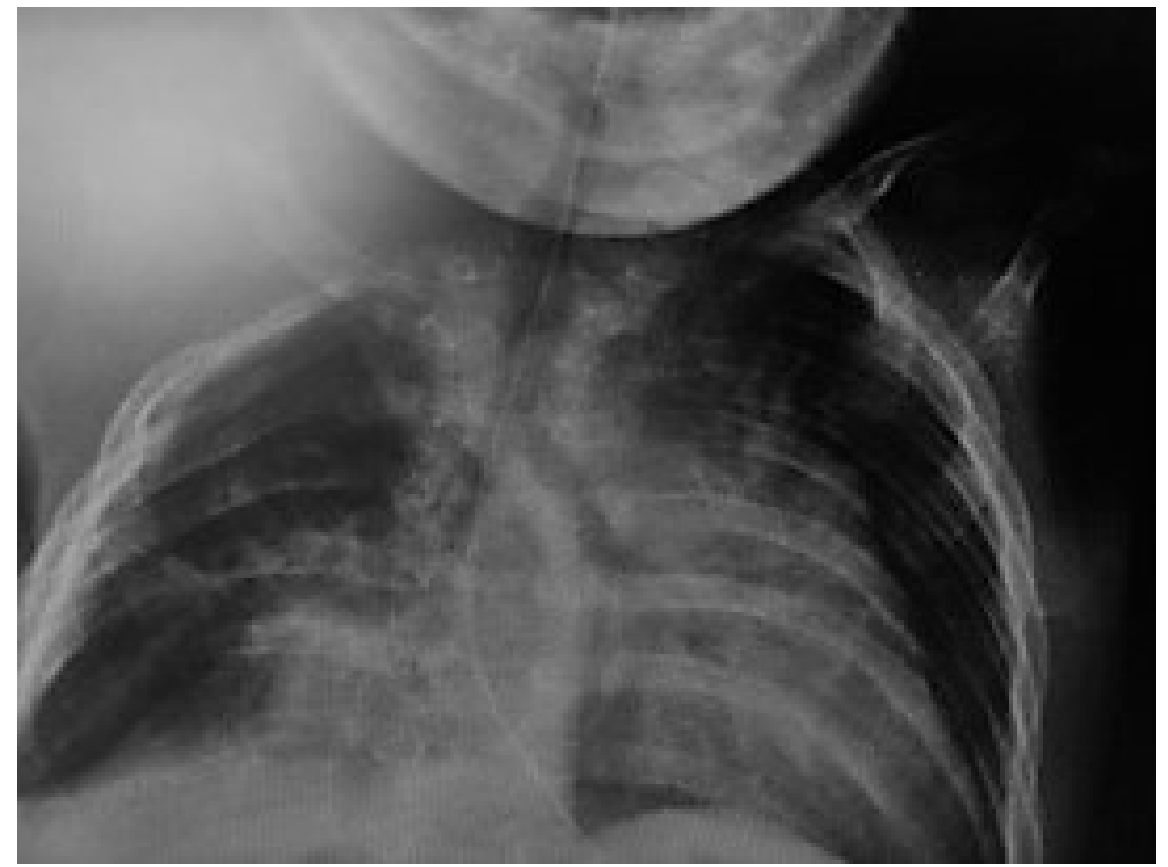

